\title{
Reply to letter from Marc Williams:
}

\section{To the Editor:}

We agree that genetic counseling and testing services have been, and continue to be, mostly utilized by Caucasian women. ${ }^{1-2}$ These findings also hold at our two study sites, Kaiser Permanente Colorado and Henry Ford Health System (HFHS). However, the thrust of our study was an assessment of change in utilization across two time periods. While outside of cancer genetics, the literature at the time of our study suggested that racial disparities in health care utilization over time are more likely to be equalized by factors other than race/ethnicity. ${ }^{3}$ As we did not see change in referrals between the two study periods at HFHS, nor in any of the geographical areas that Myriad had deemed to be control cities prior to launching their campaign, we believe that our findings as presented are valid. ${ }^{4}$

\author{
J Mouchawar MD, MSPH \\ Jennifer Ellis, MSPH, MBA \\ Debra Ritzwoller, PhD \\ Kaiser Permanente \\ Boulder, Colorado \\ Sharon Hensley-Alford, MPH \\ Henry Ford Health System \\ Detroit, Michigan \\ Suzanne Laurion, PhD \\ St. Augustine, Florida
}

Flagler College Department of Communications

\section{References}

1. Armstrong K, Weber B, Stopfer J, Calzone K, Putt M, Coyne J, et al Early use of clinical BRCA1/2 testing: associations with race and breast cancer risk. Am J Med Genet A 2003;117:154-160.

2. Armstrong K, Micco E, Carney A, Stopfer J, Putt M. Racial differences in the use of BRCA1/2 testing among women with a family history of breast or ovarian cancer. JAMA 2005;293:1729-1736.

3. Weinick RM, Zuvekas SH, Cohen JW. Racial and Ethinic Differences in Access to and Use of Health Care Services, 1977 to 1996 Medical Care Research and Review 2000;20: 36-54.

4. Myriad Genetic Laboratories, Inc. Integrated Consumer Awareness Campaign: PostPilot Evaluation. Denver, CO 2004. 